\title{
2-Aminobenzaldehydes from quinolinium salts and alkaline hydrogen peroxide
}

\author{
Ian Allan Apple and Otto Meth-Cohn* \# \\ Chemistry Department, University of Sunderland, Sunderland, SR1 3SD, UK. \\ E-mail: otto.meth-cohn@sunderland.ac.uk
}

Dedicated to Professor Charles Rees on the occasion of his $75^{\text {th }}$ birthday

(received 09 May 02; accepted $02 \mathrm{Jul} 02$; published on the web $10 \mathrm{Jul} \mathrm{02)}$

\begin{abstract}
2-Formylanilines are very handy. For building various heterocyclic rings. But making them is not so very dandy. Low yields and multi-step 'mongst other things.

$\mathrm{N}$-Alkylquinoliniums cleave with great ease. With hydrogen peroxide / aqueous base. (The mechanism's clear to such as Charles Rees). To give these anilines - good yields, good pace.
\end{abstract}

Keywords: 2-Aminobenzaldehydes, quinolinium salts, alkaline hydrogen peroxide

\section{Introduction}

2-Aminobenzaldehyde and its derivatives are key intermediates in heterocyclic synthesis. Thus the Friedländer synthesis of quinolines ${ }^{1}$ (base-catalysed condensation of 2aminobenzaldehyde with aliphatic aldehydes and ketones) is a widely used method. Both 2- and 4-quinolones ${ }^{2}$ as well as acridines and acridones ${ }^{3}$ are easily made from these versatile precursors as are indoles, ${ }^{4}$ while dimerisation of $\mathrm{N}$-methyl-2-aminobenzaldehyde yields oxa-analogues of Tröger's base. ${ }^{5}$ Various other macrocyclic applications have been described. ${ }^{6}$ Numerous quinazolines have been made efficiently ${ }^{7}$ while Michael additions of 2-aminobenzaldehydes to alkenes and alkynes present a versatile route to quinolines and fused quinolines. ${ }^{8}$

Most syntheses of 2-aminobenzaldehydes involve more than one step and at best are moderate in yield. For example, the synthesis of 2-aminobenzaldehyde itself has been reported from easily derived precursors such as 2-nitroaniline (by way of the Beech reaction, employing formaldoxime coupling with the derived diazonium salt in 33\% yield ${ }^{9}$ ) or from 2-nitrotoluene (oxidation with $\mathrm{CrO}_{3} / \mathrm{Ac}_{2} \mathrm{O}$ followed by hydrolysis of the derived aldehyde diacetate in $24 \%$ yield $^{10}$ ) (Scheme 1). 
<smiles>Cc1ccccc1[N+](=O)[O-]</smiles>
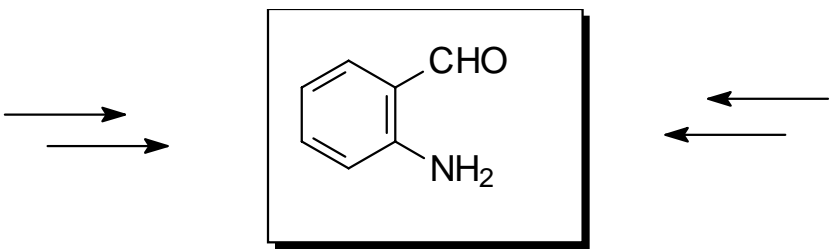<smiles>Nc1ccccc1[N+](=O)[O-]</smiles><smiles>O=Cc1ccccc1[N+](=O)[O-]</smiles>

\section{Scheme 1}

Other approaches are from condensation of 2-nitrobenzaldehyde to give 2-nitrocinnamic acid followed by oxidation, ${ }^{11}$ or from several other multi-step reactions from aniline (40-50\%). It is clear that there is a need for a simple and potentially large scale route to these versatile intermediates. In this paper we explore just such a route to $N$-alkyl-2-aminobenzaldehydes, utilising easily made quinolinium salts and their reaction with alkaline hydrogen peroxide(Scheme 2).<smiles></smiles>

1

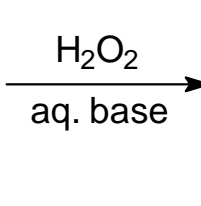<smiles>Nc1ccccc1C=O</smiles>

$2 a$

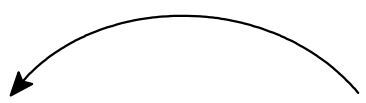<smiles>[R]N(C)c1ccccc1C=O</smiles>

2b

\section{Scheme 2}

\section{Discussion}

The initial 'standard' process. When $N$-methylquinolinium salts (1) are treated with cold aqueous sodium hydroxide and hydrogen peroxide, a fast and mildly exothermic reaction takes place, to give on work-up 2-methylaminobenzaldehyde (2a) together with its $N$-formyl derivative (2b). By varying ratios of reagents, the optimal stoichiometry for this process was found to be 2 moles each of the base and of hydrogen peroxide (33-35\% aqueous) per mole of quinolinium 
salt. Furthermore, the most effective method under these conditions was the dropwise addition of the base over 5 minutes to the other components in water maintained at about room temperature with stirring, when after 2 hours reaction, no salt $\mathbf{1}$ remained. On work-up the two products $\mathbf{2 a}$ and $\mathbf{2 b}$ were isolated in 30 and 39\% respectively. Longer reaction times allowed the sole formation of 2-methylaminobenzaldehyde $\mathbf{2 a}$, presumably by hydrolysis of any $\mathbf{2} \mathbf{b}$. Complete reaction of the salt is easily monitored by addition of ammonium hexafluorophosphate to an aliquot, the quinolinium hexafluorophosphate precipitating.

Variation of the base. Similar results were observed if triethylamine was employed instead of sodium hydroxide, though more reagent was required (4:3:1 moles of base:peroxide:salt), probably due to triethylamine $\mathrm{N}$-oxide formation. Sodium carbonate proved less effective while very useful results derived from the use of sodium phosphate $\left(\mathrm{Na}_{3} \mathrm{PO}_{4}\right)$ as the base when a combined yield of over $70 \%$ of the two products could be isolated.

Variation of the peroxidic agent. A variety of peroxidic reagents were also examined but none were as effective as aqueous hydrogen peroxide. Thus while sodium perborate reacted slowly to give solely $\mathbf{2 a}$ in $30 \%$ yield, using $\mathrm{Na}_{3} \mathrm{PO}_{4}$ as base after 16 hours reaction, t-butyl hydroperoxide, performic acid, trifluoroperacetic acid and potassium monopersulfate were totally ineffective.

Variation of the solvent. Solvents other than water (including methanol, aqueous methanol, DMSO, aqueous DMSO, acetonitrile, dioxane, and DMF) were of no benefit whatever, the more water present the better the reaction yields. However, use of a 2-phase system did prove of interest. For example, use of DCM/aqueous sodium phosphate at $0-5{ }^{0} \mathrm{C}$ for 16 hours, gave up to $80 \%$ combined yield of products $\mathbf{2 a}$ and $\mathbf{2} \mathbf{b}$. Tetrachloromethane/water also proved particularly useful in that solely 2-methylaminobenzaldehyde $2 \mathbf{a}$ was formed in 78\%. The optimal 2-phase reaction conditions, allowing solely the formation of 2-methylaminobenzaldehyde 2a in $84 \%$ yield on a $20 \mathrm{~g}$ scale (and of at least $62 \%$ on an $80 \mathrm{~g}$ scale) were use of 1,2-dichloroethane/water with dropwise addition of the salt in water to the other well stirred reactants, initially at $0-5{ }^{0} \mathrm{C}$ and then finally at ambient for 18-72h. In some cases a co-solvent aided dissolution of the salt (see below and Experimental).

Variation of the $\mathrm{N}$-substituent of the quinoline. The reaction is effective with other $\mathrm{N}$ substituted quinolines including ethyl (29 and 37\% yield of the amino- benzaldehyde $2 \mathbf{a}$ and its formyl derivative $\mathbf{2 b}$ respectively under the 'standard' conditions) and allyl (73\% of the 2allylaminobenzaldehyde with only a trace of its formyl derivative; even on a 20g scale this yield was maintained, again, under the 'standard' conditions). Several 1-substituents were readily cleaved under the reaction conditions including -methoxymethyl and -4-toluenesulfonyl.

Effect of $\boldsymbol{C}$-substituents in the quinoline. (a) 2-Methylquinolinium salts. Initial studies with sodium hydroxide and aqueous hydrogen peroxide indicated that red dye formation (presumably a cyanine-type dye from deprotonation of the 2-methyl group followed by coupling of this derived enamine with unreacted salt) was a significant pathway. Lowering the reaction temperature helped slightly. TLC suggested that both 2-methylaminobenzaldehyde and its $N$ acetyl derivative were also formed but chromatographic work-up gave solely the former product in $30 \%$ yield. Even using weaker bases such as triethylamine, dye formation still occurred. 
However, using sodium phosphate and aqueous hydrogen peroxide in a 3:3 ratio per mole of the salt, satisfactory yields of mostly the aminobenzaldehyde 2a (73\%) with a little of its acetyl derivative were achieved after 16 hours reaction at $0-5{ }^{0} \mathrm{C}$. Similarly, using the 2-phase system with tetrachloromethane and water, the yield was increased to $80 \%$, this being achievable on any scale from 2-20g of the salt and, if allowed to stir for 72 hours, produced solely 2methylaminobenzaldehyde $\mathbf{2 a}$.

(b) 4-Methylquinolinium salts. In a similar way to that observed with 2-methylquinolinium salts, the standard reaction conditions using sodium hydroxide as base caused red dye formation from the 4-methylquinolinium salt, together with up to $30 \%$ yield of 2methylaminoacetophenone and by-products. No further work was done to optimise this reaction.

(c) 6-Substituted 1-methylquinolinium salts. Only limited studies of 6-substituents was undertaken. A small amount of ethanol was necessary as a co-solvent in this series owing to the lower aqueous solubility of the salts. Thus while 6-methoxy- and 6-methyl-quinolinium salts rapidly gave reasonable yields of the corresponding 2-methylaminobenzaldehyde under the standard conditions (39 and 54\% respectively, together with the corresponding $N$-formyl derivative in 20 and $8 \%$ yield respectively) the yield of 5-methoxy-2-methylaminobenzaldehyde increased to $79 \%$ under the optimised 2-phase conditions. However, the 6-nitroquinolinium salt gave no ring opened products but solely the corresponding 2-quinolone in $33 \%$ yield.

Mechanism of the ring opening. The most reasonable explanation for this interesting ringopening reaction is depicted in Scheme 3. It is well known that quinolinium salts form carbinolamines ('pseudo bases') with base, which are in tautomeric equilibrium with 2aminocinnamaldehydes. This latter electrophilic alkene can then epoxidise with the peroxide and the epoxide is oxidatively degraded to give the products $\mathbf{2}$ in accord with known literature precedent. $^{12}$

Some new reactions of 2-methylaminobenzaldehyde. (a) 1,2-Dimethylquinolinium salt formation.- The action of acetone on 2-methylaminobenzaldehyde and base gives a yellow solution, presumably the dehydrated aldol adduct, which on heating at $70-80{ }^{\circ} \mathrm{C}$ yields a $1,2-$ dimethylquinolinium salt (precipitated as its hexafluorophosphate) in $70 \%$ yield. 


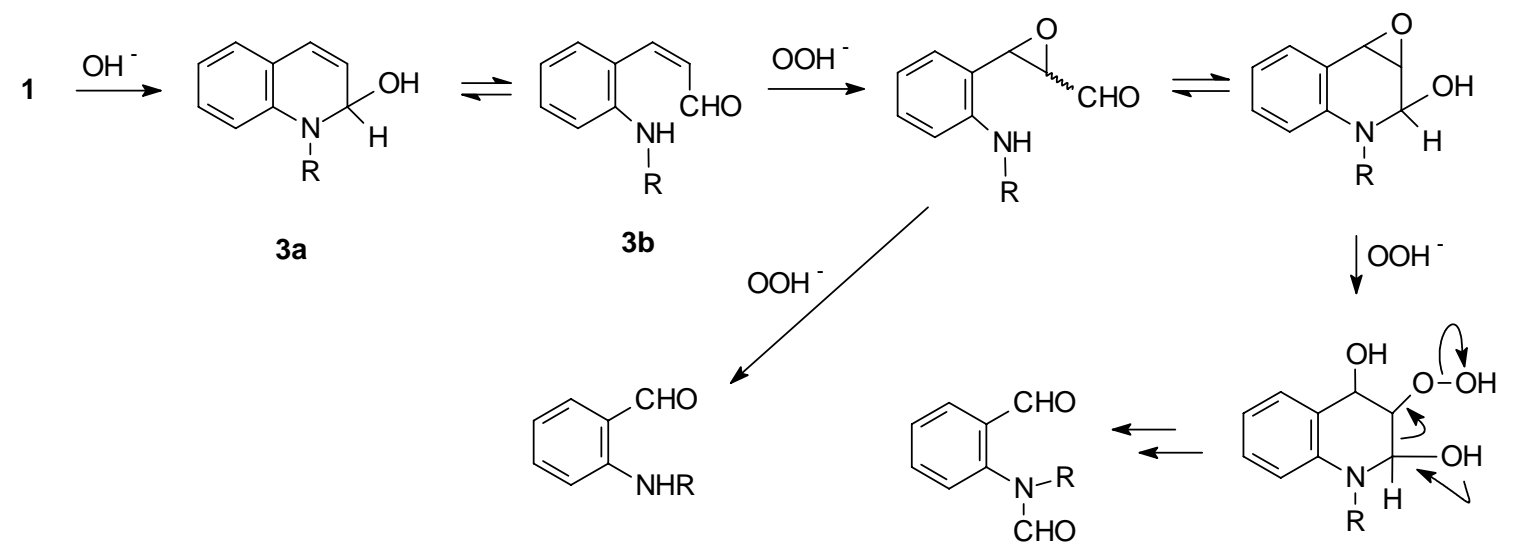

$2 a$

$2 b$

\section{Scheme 3}

(b) Michael addition-cyclisation reactions. This novel reaction proves effective in that cinnamonitrile, chalcone and coumarin each yielded an $N$-methyl-1,2-dihydro-2,3-disubstituted quinoline (4 and 5) in reasonable yields [40-70\%] as shown in Scheme 4.<smiles>CN1c2ccccc2C=C(C(=O)O)C1c1ccccc1O</smiles>

5<smiles>Cc1ccc2oc(=O)ccc2c1</smiles>

$\mathrm{NaH}, \triangle$

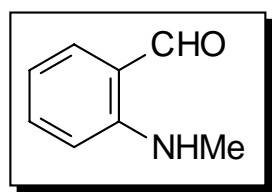

a, $\mathrm{R}=\mathrm{CN}$

b, $\mathrm{R}=\mathrm{COPh}$<smiles>[R]C1=Cc2ccccc2N(C)C1(c1ccccc1)c1ccccc1</smiles>

4

\section{Scheme 4}

(c) Darzens reactions. The interaction of 2-methylaminobenzaldehyde with ethyl chloroacetate and sodium hydride in THF solution gratifyingly gave the known ${ }^{13}$ 4-hydroxy-1-methyl-2quinolone in $65 \%$ yield.

\section{Experimental Section}

General Procedure. Melting points were taken on a Reichert hot-stage apparatus and are uncorrected. Infrared spectra were recorded on an FTIR Perkin Elmer 1720X instrument as liquid films (for oils) or $\mathrm{KBr}$ discs (for solids). NMR spectra were recorded on a JEOL 270 spectrometer. Chemical shifts are given in ppm and are referenced to the residual peak of the 
solvent or tetramethylsilane. Coupling constants are given in Hz. Accurate mass measurements were recorded on a Brüker APEX FTMS. TLC were performed using Merck silica 60F254 plates and flash chromatography with Fluka silica gel 60. Organic layers were dried over magnesium sulfate. Tetrahydrofuran (THF) was freshly distilled from sodium/benzophenone. Quinoline was distilled before use. Reactions requiring anhydrous conditions were performed in oven-dried and flamed apparatus under argon. All reactions using hydrogen peroxide were treated with thiodiethanol before further workup. The following compounds were prepared according to the literature: 1-methylquinolinium iodide $^{14}$ 1-methylquinolinium methosulfate, ${ }^{14}$ 1ethylquinolinium iodide, ${ }^{15}$ 1-allyllquinolinium bromide, ${ }^{16}$ 1-benzylquinolinium chloride, ${ }^{17} 1$ benzylquinolinium bromide, ${ }^{17}$ 1-methoxymethylquinolinium chloride, ${ }^{18}$ 1-tosylquinolinium chloride, ${ }^{19}$ 1-ethoxycarbonylmethylylquinolinium bromide, ${ }^{20}$ 1,2-dimethylquinolinium methosulfate, ${ }^{21}$ 1,4-dimethylquinolinium methosulfate, ${ }^{20}$ 1,6-dimethylquinolinium methosulfate, ${ }^{20} 6$-methoxy-1-methylquinolinium iodide, ${ }^{20} 1$-methyl-6-nitroquinolinium iodide. ${ }^{22}$

\section{General methods for the alkaline oxidative ring-opening of quinolinium salts}

Method 1. The 'standard' conditions. A solution of sodium hydroxide (886 mg, $22.14 \mathrm{mmol}$ ) and hydrogen peroxide $(1.94 \mathrm{~mL}, 35 \% \mathrm{w} / \mathrm{v}, \mathrm{d}=1.11,22.14 \mathrm{mmol})$ in water $(30 \mathrm{~mL})$ was added dropwise over $15 \mathrm{~min}$ to a stirred solution of 1-methylquinolinium iodide $(2.00 \mathrm{~g}, 7.38 \mathrm{mmol})$ in water $(50 \mathrm{~mL})$ at room temperature, when a yellow colour formed. After $2 \mathrm{~h}$, addition of ammonium hexafluorophosphate indicated that no quinolinium salt remained. Thiodiethanol ( $\sim 1 \mathrm{~g})$ was added and after $5 \mathrm{~min}$ stirring ethyl acetate $(\sim 70 \mathrm{~mL})$ was added, shaken and the organic phase was collected, washed with water and sodium sulfite solution $(10 \%)$, dried with $\left(\mathrm{MgSO}_{4}\right)$ and evaporated. The residue was purified by flash chromatography on silica gel employing ethyl acetate/hexane (30/70) as eluant to give 2-methylaminobenzaldehyde (299mg, 30\%), bp $120-121{ }^{0} \mathrm{C}$ at $10 \mathrm{~mm}$ (lit. ${ }^{23}$ bp $130{ }^{\circ} \mathrm{C}$ at $17 \mathrm{~mm}$ ). $v_{\max }$ (neat) $3345(\mathrm{NH}), 2908,2829$, 2744, 1658 (CO), 1577, 869, 752 $\mathrm{cm}^{-1} ; \delta_{\mathrm{H}}\left(\mathrm{CDCl}_{3}\right) 2.92\left(3 \mathrm{H}, \mathrm{d}, J=5.5, \mathrm{CH}_{3}\right), 6.66(1 \mathrm{H}, \mathrm{d}, J=$ 8.9, 3-H), $6.68(1 \mathrm{H}, \mathrm{m}, 5-\mathrm{H}), 7.40(1 \mathrm{H}, \mathrm{m}, 4-\mathrm{H}), 7.45$ (1H, dd, $J=7.8,1.5,6-\mathrm{H}), 9.80(1 \mathrm{H}, \mathrm{d}, J=$ $0.8, \mathrm{CHO}) ; \mathrm{m} / \mathrm{z}$ (EI) $135\left(\mathrm{M}^{+}, 59 \%\right), 134 \quad\left(\mathrm{M}^{+}-1,100 \%\right), 119,105$; and 2-(Nmethylformamido)benzaldehyde (470mg, 39\%) mp $65{ }^{0} \mathrm{C}$. Found: C, 66.2; H, 5.7; N, 8.6\%. $\mathrm{C}_{9} \mathrm{H}_{9} \mathrm{NO}_{2}$ requires C, 66.2; H, 5.6; N, 8.6\%. $v_{\max }(\mathrm{KBr})$ 2873, 1758 (CO), 1679 (CO), 1598, $773 \mathrm{~cm}^{-1} ; \delta_{\mathrm{H}}\left(\mathrm{CDCl}_{3}\right) 3.36$ and $3.45\left(3 \mathrm{H}, \mathrm{s}\right.$, rotameric $\left.\mathrm{CH}_{3}\right), 7.34(1 \mathrm{H}, \mathrm{dd}, J=7.8,1.1,3-\mathrm{H}), 7.56$ (1H, m, 5-H), $7.73(1 \mathrm{H}, \mathrm{m}, 4-\mathrm{H}), 7.99$ (1H, dd, $J=7.6,1.9,6-\mathrm{H}), 8.25$ and $8.40(1 \mathrm{H}, \mathrm{s}, \mathrm{CHO}$ rotameric), 9.99 and 10.10 (1H, s, CHO rotameric); ); m/z (EI) 163 (M+1 100\%), 148 (26\%), 134 (46\%).

Method 2. Large scale 2-phase method for the preparation of 2-methylaminobenzaldehyde. To a stirred mixture of potassium hydroxide (83g, $1.48 \mathrm{~mol})$ in water $(300 \mathrm{~mL})$ and 1,2 -dichloroethane $(300 \mathrm{~mL})$ at $0{ }^{0} \mathrm{C}$ was added hydrogen peroxide $(64 \mathrm{~mL}, 35 \% \mathrm{w} / \mathrm{v}, \mathrm{d}=$ $1.11,0.74 \mathrm{~mol})$ in water $(36 \mathrm{~mL})$. 1-Methylquinolinium iodide $(40 \mathrm{~g}, 0.148 \mathrm{~mol})$ in water $(100 \mathrm{~mL})$ was added dropwise over $45 \mathrm{~min}$ to this vigorously stirred mixture at $0{ }^{0} \mathrm{C}$, which was then allowed to rise to room temperature when it was stirred for $72 \mathrm{~h}$. Thiodiethanol ( $\sim 5 \mathrm{~g})$ was 
added and after 5 min stirring the layers were separated and the aqueous phase extracted with dichloromethane $(100 \mathrm{~mL})$. The organic phase collected, washed with water and sodium sulfite solution (10\%) dried $\left(\mathrm{MgSO}_{4}\right)$ and evaporated. The residue was distilled under vacuum to give 2-methylaminobenzaldehyde as a pale straw-coloured liquid (16.5g, 84\%).

Similar reaction on an $80 \mathrm{~g}$ scale with $18 \mathrm{~h}$ stirring gave the same product in $62 \%$ yield.

Other results are collected in the Table below.

Using the above method 1 the following other quinolinium salts were reacted:

From 6-methoxy-1-methylquinolinium iodide was obtained 4-methoxy-2methylaminobenzaldehyde (39\%), mp 52-53 ${ }^{0} \mathrm{C}$; lit. ${ }^{24} \mathrm{mp} 53-54{ }^{0} \mathrm{C} . v_{\max }$ (neat) 3359 (NH), 2945, 1650 (CO), 1579, 859, 750 $\mathrm{cm}^{-1} ; \delta_{\mathrm{H}}\left(\mathrm{CDCl}_{3}\right) 2.75\left(3 \mathrm{H}, \mathrm{d}, J=5.1, \mathrm{CH}_{3}\right), 3.64(3 \mathrm{H}, \mathrm{s}$, $\left.\mathrm{OCH}_{3}\right), 6.48(1 \mathrm{H}, \mathrm{d}, J=9.2,3-\mathrm{H}), 6.81(1 \mathrm{H}, \mathrm{d}, J=3.0,6-\mathrm{H}), 6.95(1 \mathrm{H}, \mathrm{dd}, J=9.2$ and 3.0, 4-H), 7.83 (1H, bs, NH), 9.62 (1H, s, CHO); m/z (EI) 165 (M+1, 60\%), 164 ( $\left.\mathrm{M}^{+}-1,100 \%\right), 149,135$. Using Method 2 on a $3 \mathrm{~g}$ scale the same product was obtained in $79 \%$ yield.

From 1,6-dimethylquinolinium iodide was obtained 4-methyl-2-methylaminobenzaldehyde (54\%), mp 32-33 ${ }^{0} \mathrm{C}$; lit. ${ }^{24} \mathrm{mp} 34{ }^{0} \mathrm{C}$. $v_{\max }$ (neat) 3360 (NH), 2930, 2850, 1655 (CO), 1580, 860, $740 \mathrm{~cm}^{-1} ; \delta_{\mathrm{H}}\left(\mathrm{CDCl}_{3}\right) 2.31\left(3 \mathrm{H}, \mathrm{s}, \mathrm{CH}_{3}\right), 2.90\left(3 \mathrm{H}, \mathrm{d}, J=5.4, \mathrm{NCH}_{3}\right), 6.60(1 \mathrm{H}, \mathrm{d}, J=8.9,3-\mathrm{H})$, $7.15(1 \mathrm{H}, \mathrm{dd}, J=8.9$ and 2.7, 4-H), $7.20(1 \mathrm{H}, \mathrm{d}, J=2.7,6-\mathrm{H}), 7.86(1 \mathrm{H}, \mathrm{bs}, \mathrm{NH}), 9.72(1 \mathrm{H}, \mathrm{s}$, CHO); $m / z$ (EI) 149 (M+, 65\%), $148\left(\mathrm{M}^{+}-1,100 \%\right), 133,119$.

From 1-methyl-6-nitroquinolinium iodide was obtained 1-methyl-6-nitroquinolin-2-one, (33\%), mp 148-150 ${ }^{\circ} \mathrm{C}$. (Found: C, 58.6; H, 3.9; N, 14.3\%. $\mathrm{C}_{10} \mathrm{H}_{8} \mathrm{~N}_{2} \mathrm{O}_{3}$ requires C, 58.8; H, 3.95; $\mathrm{N}, 13.7 \%$.) $\delta_{\mathrm{H}}\left(\mathrm{CDCl}_{3}\right) 3.72\left(3 \mathrm{H}, \mathrm{s}, \mathrm{CH}_{3}\right), 6.83(1 \mathrm{H}, \mathrm{d}, J=9.5,8-\mathrm{H}), 7.74(1 \mathrm{H}, \mathrm{d}, J=9.2,3-\mathrm{H})$, 8.16 (1H, dd, $J=9.2,4-\mathrm{H}), 8.42(1 \mathrm{H}, \mathrm{dd}, J=9.5$ and 2.7, 7-H), $8.73(1 \mathrm{H}, \mathrm{d}, J=2.7,5-\mathrm{H}) ; \mathrm{m} / \mathrm{z}$ (EI) $204.0543\left(\mathrm{M}^{+}, 100 \% ; \mathrm{C}_{10} \mathrm{H}_{8} \mathrm{~N}_{2} \mathrm{O}_{3}\right.$ requires 204.0535), $158\left(\mathrm{M}^{+}-\mathrm{NO}_{2}, 60 \%\right)$.

From 1-allylquinolinium bromide. To a solution of potassium hydroxide $(14.0 \mathrm{~g}, 0.25 \mathrm{~mol})$ in water $(40 \mathrm{~mL})$ at $0{ }^{0} \mathrm{C}$ was added tetrachloromethane $(80 \mathrm{~mL})$, t-butyl alcohol $(25 \mathrm{~mL})$ and 1 allylquinolinium bromide $(5.00 \mathrm{~g}, 20 \mathrm{mmol})$ in water $(20 \mathrm{~mL})$ and the mixture stirred for 1h.Hydrogen peroxide $(20 \mathrm{~mL}, 35 \%)$ was then added dropwise at the same temperature and the mixture stirred for a further $2 \mathrm{~h}$ after which the phases were separated, the aqueous phase extracted with chloroform $(100 \mathrm{~mL})$ and the combined organic phase worked up as above. 2Allylaminobenzaldehyde (2.34g, 73\%) was obtained as a pale yellow oil, b.p. $140-142{ }^{0} \mathrm{C} / 10 \mathrm{~mm}$. (Found: C, 74.2; H, 6.6; N, 9.3\%. $\mathrm{C}_{10} \mathrm{H}_{11} \mathrm{NO}$ requires C, 74.5; H, 6.9; N, 8.7\%.) $\delta_{\mathrm{H}}\left(\mathrm{CDCl}_{3}\right) 3.77$ $\left(2 \mathrm{H}, \mathrm{m}, \mathrm{N}-\mathrm{CH}_{2}\right), 5.08\left(1 \mathrm{H}, \mathrm{ddd}, J=10.3,1.6\right.$ and 1.6, $\left.=\mathrm{CH}_{2}\right), 5.17(1 \mathrm{H}, \mathrm{dt}, J=17.3,1.6$ and 1.6, $\left.=\mathrm{CH}_{2}\right), 17(1 \mathrm{H}, \mathrm{dt}, J=17.3,10.3$ and 5.9, $=\mathrm{CH}), 6.54(1 \mathrm{H}, \mathrm{d}, J=8.1,3-\mathrm{Ar}-\mathrm{H}), 6.58(1 \mathrm{H}, \mathrm{m}, 5-$ Ar-H), 7.25 (1H, m, 4-Ar-H), 7.45 (1H, dd, $J=7.8$ and 1.6, 6-Ar-H), $8.36(1 \mathrm{H}, \mathrm{s}, \mathrm{CHO}) ; \mathrm{m} / \mathrm{z}$ (EI) $161\left(\mathrm{M}^{+}, 100 \%\right), 131\left(\mathrm{M}^{+}-\mathrm{CHO}, 65 \%\right)$. 


\section{Reactions of 2-methylaminobenzaldehyde}

Formation of 1,2-dimethylquinolinium iodide. A mixture of 2-methylaminobenzaldehyde $(2.00 \mathrm{~g}, 12.4 \mathrm{mmol})$ in a mixture of acetone $(20 \mathrm{~mL})$, ammonium hydroxide $(5 \mathrm{~mL}, \mathrm{~d}, 0.880)$, water $(10 \mathrm{~mL})$ and dioxane $(10 \mathrm{~mL})$ was stirred at room temperature and then treated with lithium hydroxide (2g). After $1 \mathrm{~h}$ stirring a bright yellow product was evident by TLC and the mixture was heated at $70-80{ }^{0} \mathrm{C}$ for $3 \mathrm{~h}$ when the bright yellow material disappeared. The mixture was diluted with water $(50 \mathrm{~mL})$ and ammonium hexafluorophosphate (2.5g) was added. The colourless precipitate was filtered washed with water and dried and treated with sodium iodide in refluxing chloroform. Sodium hexafluorophosphate was filtered off and diethyl ether added to the hot chloroform solution to cause 1,2-dimethylquinolinium iodide to crystallise (2.40g, $70 \%$ ), mp 193-195 ${ }^{0} \mathrm{C}$, identical to the sample prepared above.

Formation of 3-cyano-1-methyl-2-phenyl-1,2-dihydroquinoline (4a). Sodium hydride (1.78g, $60 \%$ dispersion in oil, $44.4 \mathrm{mmol}$ ) was carefully added to a stirred solution of 2methylaminobenzaldehyde $(2.00 \mathrm{~g}, 14.8 \mathrm{mmol})$ in dioxane $(30 \mathrm{~mL})$. After $10 \mathrm{~min}$. cinnamonitrile (2.30g, $17.8 \mathrm{mmol}$ ) was carefully added to give a pale green mixture which was heated and stirred at $80-90{ }^{0} \mathrm{C}$ for $6 \mathrm{~h}$. The cooled solution was poured into aqueous $\mathrm{KH}_{2} \mathrm{PO}_{4}(200 \mathrm{~mL}, 5 \%)$ and then extracted with ethyl acetate $(2 \times 100 \mathrm{~mL})$, the organic phase separated, dried $\left(\mathrm{MgSO}_{4}\right)$ and evaporated. The crude product (3.20g) was recrystallised as a fluorescent pale green solid (0.80g, 22\%) from ethyl acetate and light petroleum (bp 60-80 ${ }^{0} \mathrm{C}$ ), mp 108-110 ${ }^{0} \mathrm{C}$. (Found: C, 82.9; H, 5.7; N, 11.4\%. $\mathrm{C}_{17} \mathrm{H}_{14} \mathrm{~N}_{2}$ requires C, 82.9; H, 5.7; N, 11.4\%.). v $\max (\mathrm{KBr}) 2204(\mathrm{CN})$, 1623, 1594, 786, 761, 744 $\mathrm{cm}^{-1} ; \delta_{\mathrm{H}}\left(\mathrm{CDCl}_{3}\right) 2.77$ (3H, s, $\left.\mathrm{CH}_{3}\right), 5.16(1 \mathrm{H}, \mathrm{s}, C H \mathrm{Ph}), 6.49(1 \mathrm{H}, \mathrm{d}, J$ = 8.4, 8-H), $6.66(1 \mathrm{H}$, ddd, $J=7.6,7.3$ and 0.8, 6-H), $7.00(1 \mathrm{H}, \mathrm{dd}, J=7.6$ and 1.6, 5-H), 7.06 $(1 \mathrm{H}, \mathrm{s}, \mathrm{CH}=\mathrm{C}), 7.22$ (1H, ddd, $J=8.4,7.6$ and 1.6, 7-H), 7.26-7.31 (5H, m, Ph); m/z (EI) 246 $\left(\mathrm{M}^{+}, 44 \%\right), 218\left(\mathrm{M}^{+}-\mathrm{CN}, 8 \%\right), 169\left(\mathrm{M}^{+}-\mathrm{Ph}, 100 \%\right)$.

Formation of 1-methyl-3-benzoyl-2-phenyl-1,2-dihydroquinoline (4b). Sodium hydride (1.78g, 60\% dispersion in oil, $44.4 \mathrm{mmol}$ ) was carefully added to a stirred solution of 2methylaminobenzaldehyde $(2.00 \mathrm{~g}, 14.8 \mathrm{mmol})$ in piperidine $(20 \mathrm{~mL})$. After $10 \mathrm{~min}$. chalcone (3.70g, $17.8 \mathrm{mmol}$ ) was carefully added producing an exotherm, to give an amber mixture. After $30 \mathrm{~min}$. the mixture was heated and stirred at 70-80 ${ }^{0} \mathrm{C}$ for $1 \mathrm{~h}$. The cooled solution was poured into aqueous $\mathrm{KH}_{2} \mathrm{PO}_{4}(200 \mathrm{~mL}, 5 \%)$ and then extracted with ethyl acetate (2x100mL), the organic phase separated, dried $\left(\mathrm{MgSO}_{4}\right)$ and evaporated. The crude product (4.10g) was recrystallised twice from light petroleum (bp $60-80{ }^{0} \mathrm{C}$ ) to give the title product as amber crystals $(2.70 \mathrm{~g}, 56 \%)$ mp 132-134 ${ }^{0} \mathrm{C}$. (Found: C, 84.9; H, 5.9; N, 4.3\%. $\mathrm{C}_{23} \mathrm{H}_{19} \mathrm{NO}$ requires C, 84.9; H, 5.9; N, 4.3\%.). $v_{\max }(\mathrm{KBr}) 1623(\mathrm{CO}), 1596,719,696 \mathrm{~cm}^{-1} ; \delta_{\mathrm{H}}\left(\mathrm{CDCl}_{3}\right) 2.86\left(3 \mathrm{H}, \mathrm{s}, \mathrm{CH}_{3}\right), 5.83(1 \mathrm{H}, \mathrm{s}, \mathrm{CHPh})$, $6.54(1 \mathrm{H}, \mathrm{d}, J=8.6,8-\mathrm{H}), 6.61(1 \mathrm{H}$, ddd, $J=7.6,7.3$ and $0.8,6-\mathrm{H}), 7.00(1 \mathrm{H}, \mathrm{dd}, J=7.3$ and 1.6, 5-H), 7.11 (1H, s, CH=C), 7.15-7.30 ((5H, m, Ph), 7.32-7.50 (4H, m), 7.30 (2H, m); m/z (EI) $325\left(\mathrm{M}^{+}, 40 \%\right), 248$ ( $\left.\mathrm{M}^{+}-\mathrm{Ph}, 100 \%\right), 220\left(\mathrm{M}^{+}-\mathrm{COPh}, 16 \%\right)$.

Formation of 2-(2-hydroxyphenyl)-1-methyl-1,2-dihydroquinoline-3-carboxylic acid (5). Sodium hydride $(1.78 \mathrm{~g}, 60 \%$ dispersion in oil, $44.4 \mathrm{mmol}$ ) was carefully added to a stirred solution of 2-methylaminobenzaldehyde $(2.00 \mathrm{~g}, 14.8 \mathrm{mmol})$ in dioxane $(30 \mathrm{~mL})$. After $10 \mathrm{~min}$. 
coumarin (2.60g, $17.8 \mathrm{mmol}$ ) was carefully added producing an amber mixture which was heated and stirred at $80-90{ }^{0} \mathrm{C}$ for $16 \mathrm{~h}$. The cooled solution was poured into aqueous $\mathrm{KH}_{2} \mathrm{PO}_{4}(200 \mathrm{~mL}$, $5 \%)$ and then extracted with ethyl acetate $(2 \times 100 \mathrm{~mL})$, the organic phase separated, dried $\left(\mathrm{MgSO}_{4}\right)$ and evaporated. The crude product (3.80g) was passed through a short column of silica gel in ethyl acetate solution, the solvent removed and the residue recrystallised from chloroform to give the title product as amber crystals $(1.90 \mathrm{~g}, 46 \%) \mathrm{mp} 177-180{ }^{0} \mathrm{C}$. (Found: $\mathrm{C}, 71.05 ; \mathrm{H}, 4.9$; $\mathrm{N}, 4.7 \%$. $\mathrm{C}_{17} \mathrm{H}_{15} \mathrm{NO}_{3}$ requires $\mathrm{C}, 72.6 ; \mathrm{H}, 5.4 ; \mathrm{N}, 5.0 \%$.). $v_{\max }(\mathrm{KBr}) 3376(\mathrm{OH}), 1666(\mathrm{CO})$, $1617,1600,840 \mathrm{~cm}^{-1} ; \delta_{\mathrm{H}}\left(\mathrm{CDCl}_{3}\right) 2.79\left(3 \mathrm{H}, \mathrm{s}, \mathrm{CH}_{3}\right), 5.93(1 \mathrm{H}, \mathrm{s}, \mathrm{CHPh}), 6.43(1 \mathrm{H}, \mathrm{d}, J=8.1,3$ '$\mathrm{H}), 6.62(1 \mathrm{H}$, ddd, $J=7.6,6.8$ and 0.8, 5’-H), $6.62(1 \mathrm{H}$, ddd, $J=7.6,7.3$ and 0.8, 6-H), $6.83(1 \mathrm{H}$, dd, $J=8.6$ and 1.4, 8-H), 7.02-7.07 (2H, m), 7.06 (1H, s, CH=C), 7.15 (1H, ddd, $J=8.6,7.6$ and 1.6, 7-H), $7.22\left(1 \mathrm{H}\right.$, dd, $J=7.6$ and 1.6, 5-H), $7.61(1 \mathrm{H}, \mathrm{s}, \mathrm{CH}=\mathrm{C}) ; \mathrm{m} / \mathrm{z}(\mathrm{EI}) 281\left(\mathrm{M}^{+}, 93 \%\right)$, 262 (25\%), $236\left(\mathrm{M}^{+}-\mathrm{CO}_{2}, 64 \%\right), 188\left(\mathrm{M}^{+}-\mathrm{PhO}, 100 \%\right)$.

Formation of 4-hydroxy-1-methylquinolin-2-one. Sodium hydride (1.78g, 60\% dispersion in oil, $44.4 \mathrm{mmol}$ ) was carefully added to a stirred solution of 2-methylaminobenzaldehyde (2.00g, $14.8 \mathrm{mmol})$ in THF (30mL) and the mixture cooled to $0-5{ }^{0} \mathrm{C}$. Ethyl chloroacetate $(4.04 \mathrm{~g}, 32.6$ mmol) was added maintaining cooling and the solution stirred at this temperature for a further 4h. The solution was poured into aqueous $\mathrm{KH}_{2} \mathrm{PO}_{4}(200 \mathrm{~mL}, 5 \%)$ and then extracted with ethyl acetate $(2 \times 100 \mathrm{~mL})$, the organic phase separated, dried $\left(\mathrm{MgSO}_{4}\right)$ and evaporated. The remaining oil was eluted through flash silica gel using firstly light petroleum (bp 60-80 ${ }^{0} \mathrm{C}$ ) then with increasing amounts of dichloromethane and finally with dichloromethane. The product from evaporation of the last solvent crystallised to give the known ${ }^{13}$ title product as amber crystals (1.70g, 65\%) mp 268-270 ${ }^{0} \mathrm{C}$ (Lit. $\mathrm{mp}^{13} 270{ }^{0} \mathrm{C}$ ). $v_{\max }(\mathrm{KBr}) 3380$ (OH), 2854, 1656 (CO), 1598, 1459, 1450, 1342, 752 $\mathrm{cm}^{-1} ; \delta_{\mathrm{H}}\left(\mathrm{CDCl}_{3}\right) 3.81\left(3 \mathrm{H}, \mathrm{s}, \mathrm{CH}_{3}\right), 7.10(1 \mathrm{H}, \mathrm{s}, 3-\mathrm{H}), 7.25(1 \mathrm{H}, \mathrm{s}, \mathrm{OH})$, 7.26 (1H, ddd, $J=7.6,7.0$ and 1.1, 6-H), $7.34(1 \mathrm{H}, \mathrm{d}, J=8.4,8-\mathrm{H}), 7.44$ (1H, ddd, $J=8.4,7.0$ and 1.6, 7-H), 7.49 (1H, dd, $J=7.6$ and 1.6, 5-H), $7.61(1 \mathrm{H}, \mathrm{s}, \mathrm{CH}=\mathrm{C}) ; \mathrm{m} / \mathrm{z}(\mathrm{EI}) 175\left(\mathrm{M}^{+}, 100 \%\right)$, 147 (50\%), $118\left(\mathrm{M}^{+}, 32 \%\right)$. 
Table 1. Reactions of quinolinium salts with base and peroxide

\begin{tabular}{|c|c|c|c|c|c|c|c|c|c|c|}
\hline \multirow{2}{*}{\multicolumn{3}{|c|}{$\begin{array}{l}\text { Quinolinium salt (1) } \\
{[1 \mathrm{M}]}\end{array}$}} & \multirow{4}{*}{$\begin{array}{l}\text { Base } \\
{[\mathrm{M}]}\end{array}$} & \multirow{4}{*}{$\begin{array}{l}\mathrm{H}_{2} \mathrm{O}_{2} \\
{[\mathrm{M}]}\end{array}$} & \multirow{4}{*}{$\begin{array}{l}\text { Co- } \\
\text { solvent }\end{array}$} & \multirow{4}{*}{$\begin{array}{l}\text { Temp } \\
{\left[{ }^{\circ} \mathrm{C}\right]^{\mathrm{a}}}\end{array}$} & \multirow{4}{*}{$\begin{array}{l}\text { Time } \\
{[\mathrm{h}]}\end{array}$} & \multicolumn{3}{|c|}{ Product(s) [\%] } \\
\hline & & & & & & & & & $2 \mathrm{~b}$ & Others \\
\hline $\mathrm{R}$ & & $X^{-}$ & & & & & & & & \\
\hline \multicolumn{6}{|c|}{ Scale[g] } & & & & & \\
\hline $\mathrm{Me}$ & I & 2 & $\mathrm{NaOH}[2]$ & [2] & -- & RT & 2 & 23 & 36 & \\
\hline $\mathrm{Me}$ & I & 2 & “ $[0.2]$ & [2] & -- & RT & 2 & 5 & 5 & \\
\hline $\mathrm{Me}$ & I & 2 & [1] & [2] & -- & RT & 2 & 17 & 22 & \\
\hline Me & I & 2 & [3] & [3] & -- & RT & 2 & 30 & 39 & \\
\hline Me & I & 2 & [2] & {$[2]^{\mathrm{b}}$} & -- & 20 & 2 & 26 & 35 & \\
\hline $\mathrm{Me}$ & I & 2 & [2] & {$[2]^{\mathrm{c}}$} & -- & 20 & 2 & 30 & 39 & \\
\hline $\mathrm{Me}$ & I & 2 & $\mathrm{Na}_{2} \mathrm{CO}_{3}[1.5]$ & 5] [3] & -- & RT & 16 & 24 & 30 & \\
\hline $\mathrm{Me}$ & I & 2 & $\mathrm{Et}_{3} \mathrm{~N}[4]$ & [3] & -- & RT & 2 & 31 & 39 & \\
\hline $\mathrm{Me}$ & I & 2 & $\mathrm{Na}_{3} \mathrm{PO}_{4}[1]$ & [3] & -- & 0 & 2 & \multicolumn{3}{|c|}{ 61(combined) } \\
\hline $\mathrm{Me}$ & I & 2 & $\mathrm{Na}_{3} \mathrm{PO}_{4}[1]$ & {$[3]^{\mathrm{d}}$} & -- & 0 & 2 & 30 & 0 & \\
\hline $\mathrm{Me}$ & I & 2 & $\mathrm{NaOH}[2]$ & [2] & $\mathrm{CCl}_{4}$ & $0-5$ & 16 & 78 & 0 & \\
\hline Me & I & 40 & KOH [10] & [5] & $\mathrm{C}_{2} \mathrm{H}_{4} \mathrm{Cl}_{2}$ & $0-20$ & 72 & 84 & & \\
\hline Et & I & 2 & $\mathrm{NaOH}$ [2] & [2] & -- & RT & 2 & 29 & 37 & \\
\hline Allyl & $\mathrm{Cl}$ & 2 & $\mathrm{NaOH}[2]$ & [2] & -- & $0-20$ & 3 & 73 & $<5$ & \\
\hline $\mathrm{Me}^{\mathrm{e}}$ & I & 2 & $\mathrm{KOH}$ [10] & [5] & $\mathrm{C}_{2} \mathrm{H}_{4} \mathrm{Cl}_{2}$ & $0-20$ & 72 & 80 & & \\
\hline$M e^{f}$ & $\mathrm{MeSO}_{4}$ & 20 & $\mathrm{NaOH}[2]$ & [2] & EtOH & 0 & 2 & -- & -- & $30^{\mathrm{f}}$ \\
\hline
\end{tabular}

(a) $\mathrm{RT}=$ room temperature with no temp. control; the reaction temp. rose to $\sim 70{ }^{\circ} \mathrm{C}$.

(b) Peroxide added to salt + base.

(c) Base added to salt + peroxide.

(d) $\mathrm{NaBO}_{3}$ used instead of hydrogen peroxide.

(e) 2-Methylquinoline methiodide used.

(f) 4-Methylquinoline methosulfate used; product was 2-methylaminoacetophenone.

\section{References}

\# This inadequate paper is dedicated to my very good friend Charles Rees on his $75^{\text {th }}$ birthday. He is not only one of the finest chemists around today, but is an exceptional gentleman and raconteur par excellence.

1. (a) Friedländer, P. Ber. 1882, 15, 2572. (b) Friedländer, P.; Gohring, C. F. Ber. 1883, 16, 1833.

2. Anderson W. K.; Dalvie, D. K. J. Heterocycl. Chem. 1993, 30, 1533 and refs. therein.

3. Hughes, G. K.; Ritchie, E. Austrl. J. scient. Res. 1951, A4, 423 and refs. therein. 
4. Gluud, W. Ber 1915, 48, 420.

5. Albert, A.; Yamamoto, H. J. Chem. Soc., Chem. Commun. 1968, 1944.

6. Owston, P. G.; Peters, R.; Ramasammy, E. Tasker, P A.; Trotter, J. J. Chem. Soc., Chem. Commun. 1980, 1218.

7. Kanmacher, I.; Stambach, J.-F.; Jung, L. Heterocycles 1990, 31, 2131 and refs. therein.

8. Rao, A. V. R.; Yadav , J. S.; Valluri, M. Tetrahedron Lett. 1994, 35, 3613 and refs. therein.

9. Beech, W. F. J. Chem. Soc. 1954, 1297.

10. Tsang, S. M.; Wood, E. H.; Johnson, J. R. Org. Synth., Coll. Vol. III 1955, 641.

11. Reddy, C. S.; Sundaraman, E. V. Tetrahedron 1989, 45, 2109.

12. Attygalle, A. B.; Morgan, E. D. Anal. Chem. 1983, 55, 1379 [ $\left.\mathrm{H}_{5} \mathrm{IO}_{6}\right]$; Wright, P.; Abbot, J. Int. J. Chem. Kinet. 1993, 25, 901 [aqueous base, room temp.] .

13. Buckle, D. R.; Cantello, B. C. C.; Smith, H.; Spicer, B. A. J. Med. Chem. 1975, 18, 726.

14. Minamikawa, J.; Brossi, A. Tetrahedron Lett. 1978, 19, 3085.

15. Dehn, W. M.; Cope, H. J. Am. Chem. Soc. 1926, 48, 2673.

16. Kroehnke, F.; Vogt, K. Chem. Ber. 1953, 86, 1504.

17. Claus, A.; Tosse, F. Chem. Ber. 1883, 16, 1278.

18. Litterscheid, F. M.; Thimme, K. Liebigs Ann. Chem. 1904, 334, 963.

19. Takahashi, H. J. Pharm. Soc. Japan. 1955, 75, 1434.

20. Ziegler, E.; Wittman, H.; Wolfbeis, O. S.; Sterk, H. Monatsh. Chem. 1984, 115, 1165.

21. Cook, M. J.; Katritzky, A. R.; Linda, P.; Tack, R. D. J. Chem. Soc., Perkin Trans. 2 1973, 1080.

22. Bunting, J. W.; Meathrel, W. G. Can. J. Chem. 1974, 52, 962.

23. Baum, J. S. Condon, M. E.; Shook, D. A. J. Org. Chem. 1987, 52, 2983.

24. Georgarakis, E.; Schmid, H.; Hansen, H. J. Helv. Chim. Acta. 1979, 62, 234. 